\title{
Synovial fluid a-defensin in the diagnosis of periprosthetic joint infection: the lateral flow test is an effective intraoperative detection method
}

\author{
Xuequan $\operatorname{Han}^{1+}$, Kai Xie ${ }^{1 \dagger}$, Xu Jiang ${ }^{1}$, Liao Wang ${ }^{1}$, Haishan Wu' ${ }^{1}$ Xinhua Qu ${ }^{2}$ and Mengning Yan ${ }^{1 *}$ (D)
}

\begin{abstract}
Background: Synovial fluid a-defensin is a valuable biomarker for periprosthetic joint infection (PJI). Its diagnostic value for PJI has been widely evaluated recently, but results are inconsistent, especially for different test methods. The objective of this study was to evaluate the diagnostic value of laboratory-based immunoassay and lateral flow testing for the detection of a-defensin against hip and knee PJI.

Methods: We systematically searched MEDLINE and EMBASE for articles on the diagnostic accuracy of a-defensin for PJl published up to September 2018. The pooled sensitivity, specificity, area under the curve (AUC), positive likelihood ratio (PLR), negative likelihood ratio (NLR), and diagnostic odds ratio (DOR) were calculated for the evaluation of the diagnostic value of a-defensin for PJl.

Results: Nineteen studies were included. Eleven evaluated laboratory-based immunoassay, and 10 evaluated the lateral flow test results. The pooled sensitivity, specificity, AUC, PLR, NLR, and DOR of laboratory-based immunoassays were 0.96 (95\% confidence interval [Cl] 0.90-0.98), 0.97 (95\% Cl 0.95-0.99), 0.99 (95\% Cl 0.98-1.00), 35.0 (95\% Cl 18.5-66.2), 0.04 (95\% Cl 0.02-0.11), and 811 (95\% Cl 220-2990), respectively. The pooled sensitivity, specificity, AUC, PLR, NLR, and DOR of the lateral flow test were 0.86 ( $95 \% \mathrm{Cl} 0.81-0.91), 0.96$ (95\% Cl 0.93-0.98), 0.95 (95\% Cl 0.93-0.97), 21.2 (95\% Cl 11.7-38.5), 0.14 (95\% Cl 0.10-0.21), and 148 (95\% Cl 64-343), respectively.

Conclusions: Laboratory-based immunoassay of a-defensin is highly accurate for the diagnosis of hip and knee PJ. The lateral flow test is less sensitive but still a useful intraoperative detection tool for PJI.
\end{abstract}

Keywords: a-Defensin, Periprosthetic joint infection, Arthroplasty, Biomarker, Diagnosis

\section{Background}

Total joint arthroplasty (TJA) is an effective treatment for advanced joint disease [1]. However, periprosthetic joint infection (PJI) is a serious complication after TJA, which often poses a threat to patient health and leads to economic burdens [2]. Although standardized surgical procedures and perioperative management have reduced the incidence of hip and knee PJI to $1-2 \%$, PJI is still an important reason for revision surgery $[3,4]$. Previous

\footnotetext{
*Correspondence: yanmengning@163.com

${ }^{+}$Xuequan Han and Kai Xie contributed equally to this work.

'Shanghai Key Laboratory of Orthopaedic Implants, Department of Orthopaedic Surgery, Shanghai Ninth People's Hospital, Shanghai Jiao Tong University School of Medicine, 639 Zhizaoju Road, Shanghai, China Full list of author information is available at the end of the article
}

studies reported that PJI accounted for $14.5 \%$ of revision total hip arthroplasties and $25 \%$ of revision total knee arthroplasties [5, 6]. Given the different treatment options for PJI and aseptic loosening, accurate and timely diagnosis is valuable in revision surgery [3]. Unfortunately, the identification of PJI and aseptic loosening remains a challenge due to the lack of a gold standard test. Serologic examination and bacterial culture have always been common tests for PJI [1]. However, a previous meta-analysis showed that the sensitivity and specificity of serum C-reactive protein (CRP) levels for PJI were 0.82 and 0.77 , respectively [7]. In addition, the pooled sensitivity of synovial fluid aspiration culture for PJI was only $0.72[8]$. 
In the past few years, the diagnostic accuracy of $\alpha$ defensin for PJI has been widely evaluated, and some of these results show great reliability [9-27]. Alpha-defensin is a cysteine-rich antimicrobial peptide that exists in many types of cells in the body [28-31]. As an innate immune response to the invasion of pathogens, $\alpha$-defensin can be released by activated neutrophils to exert antibacterial activity [29]. One genomic study showed that the expression and release of $\alpha$-defensin is a specific response of neutrophils to infectious arthritis that is not affected by non-infectious inflammation, such as acute gouty arthritis [32]. This suggests that $\alpha$-defensin has the potential to be an accurate indicator in the diagnosis of PJI. Currently, synovial fluid $\alpha$-defensin can be detected by both laboratorybased immunoassay and a lateral flow test. In the former, synovial fluid is sent to an advanced laboratory within 24 $h$ and measured via standard enzyme-linked immunosorbent assay (ELISA). The lateral flow test is a rapid detection device that can be used for intraoperative PJI diagnosis.

Before this study, some meta-analyses evaluated the diagnostic value of $\alpha$-defensin in PJI and showed that the laboratory-based immunoassay has a very high diagnostic value, whereas the lateral flow test is less accurate [33-38]. However, only up to six studies on the lateral flow test were included. After these studies, the diagnostic accuracy of $\alpha$-defensin for PJI has been widely assessed with inconsistent results [22, 24, 26, 39-43]. Therefore, the purpose of the current meta-analysis was to reassess the diagnostic value of laboratory-based immunoassay and the lateral flow test for the detection of synovial fluid $\alpha$-defensin against PJI.

\section{Methods}

The design and implementation of this study was based on the Preferred Reporting Items for Systematic Reviews and Meta-Analyses (PRISMA) statement [44].

\section{Search strategy}

Two independent reviewers systematically searched for articles on the diagnostic value of $\alpha$-defensin in PJI in the MEDLINE and EMBASE databases from the inception of the databases until September 2018. The search terms were as follows: $\alpha$-defensin, alpha-defensin, synovial fluid, biomarker, inflammatory, arthroplasty or replacement, sensitivity or specificity, septic, aseptic or aseptic loosening, prosthesis infection, infectious or infected, and diagnose or diagnostic. Additional studies were identified from the bibliographies of relevant articles.

\section{Eligibility criteria}

Studies included in our meta-analysis complied with the following criteria: (1) studies that evaluated the accuracy of $\alpha$-defensin for the diagnosis of PJI with the original or updated Musculoskeletal Infection Society (MSIS) criteria
[45, 46], (2) the patients included in studies received the test clinically, (3) studies that provided data for true-positive, false-negative, false-positive, and true-negative findings for the comparison of $\alpha$-defensin detection with the reference standard, (4) articles written in the English language, and (5) non-human experiments. Case reports were excluded.

The quality of all studies was independently evaluated using the Quality Assessment of Diagnostic Accuracy Studies (QUADAS) tool [47]. All divergences were negotiated with the assistance of a third investigator.

\section{Data extraction}

Two reviewers used standardized forms to independently extract the characteristics of the included studies. The characteristics to be extracted included the following items: authors' names, year of publication, number and mean age of patients, country in which the study was performed, study design, type of patient enrolment, test method, exclusion of patients who have been treated with antibiotics, and site of arthroplasty. A third independent reviewer helped to resolve all disagreements between the first two reviewers in the data extraction process.

\section{Statistical analysis}

True-positive, false-negative, false-positive, and truenegative rates were extracted from the included studies. Pooled sensitivity, specificity, area under the curve (AUC), and diagnostic odds ratio (DOR) were calculated to estimate the capability to identify PJI and aseptic loosening. We used positive likelihood ratio (PLR), negative likelihood ratio (NLR), and post-test probability to assess the clinical utility of the $\alpha$-defensin test for diagnosis of PJI. We calculated $I^{2}$ to assess the heterogeneity of studies [48]. An $I^{2}$ value $>50 \%$ indicated substantial heterogeneity among studies, and the diagnostic accuracy of $\alpha$ defensin for the diagnosis of PJI was calculated using the random effects model [49]. We performed subgroup analysis to explore the influence of various factors that affect the diagnostic accuracy of the above two $\alpha$-defensin tests for PJI. Deeks' funnel plot asymmetry test was used to estimate publication bias [50]. All statistical analyses were performed using STATA version 14 (StataCorp, College Station, TX, USA).

\section{Results}

\section{Search results}

We obtained 203 articles by searching databases and the bibliographies of identified articles. We excluded 175 articles after reading the title and abstract and seven articles after reading the full text (Fig. 1).

Finally, 19 articles were included in the study (Table 1). All articles were published between 2014 and 2018 . 


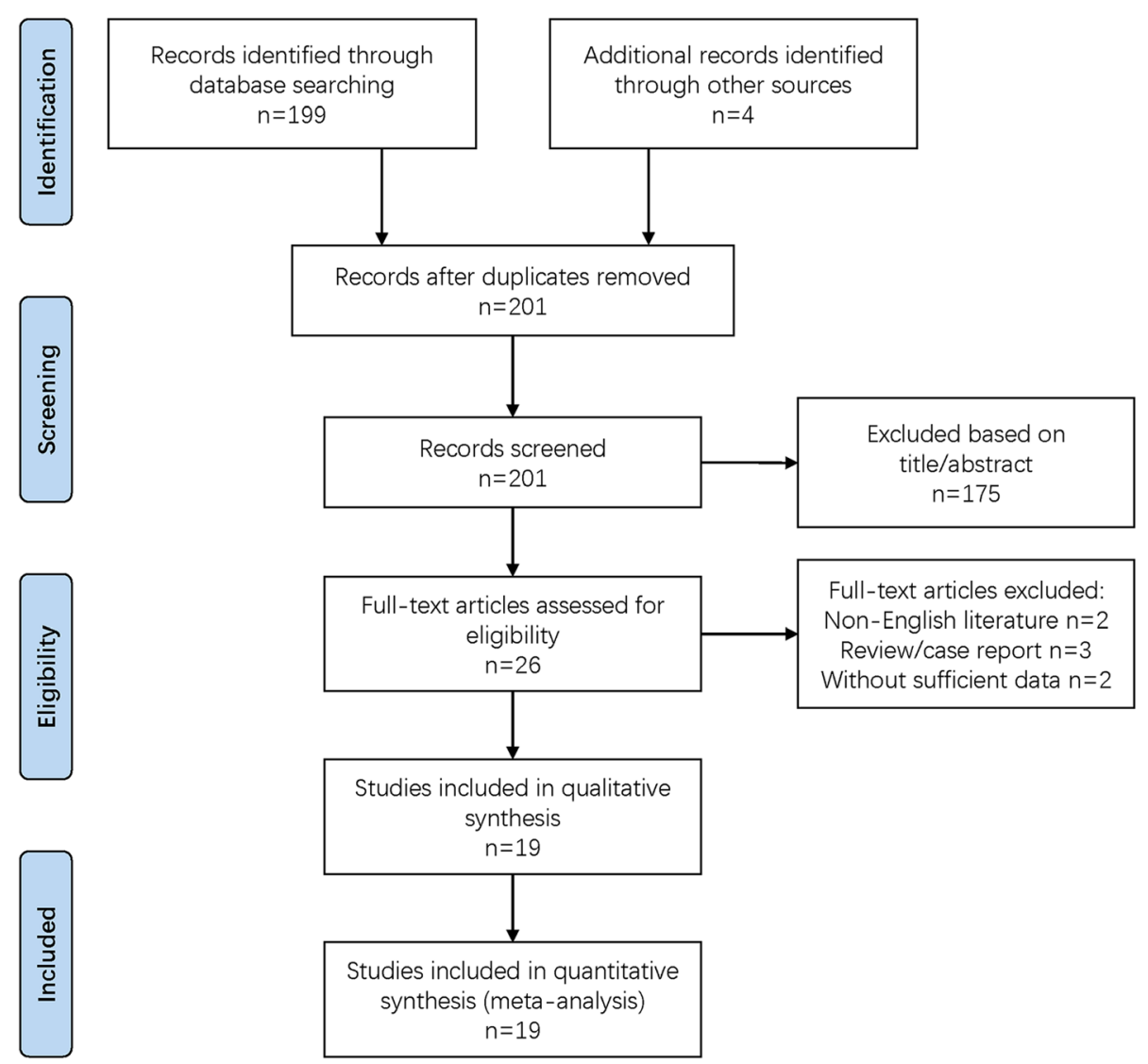

Fig. 1 Flow diagram for study selection

These 19 studies included 2043 patients who underwent revision surgery, 609 of whom were diagnosed with PJI. Eight studies were conducted in the USA and 11 were conducted in Europe. The average age of patients in all studies ranged from 62 to 71 years. Thirteen studies were prospective designs, and the others were retrospective designs. All studies were conducted on the hip and/or knee joints and used the Musculoskeletal Infection Society (MSIS) criteria to determine the diagnosis of PJI. To detect synovial fluid $\alpha$-defensin, 11 studies (1110 patients in total) used a laboratory-based immunoassay and 10 studies (933 patients in total) used the lateral flow test. In the QUADAS tool evaluation, all studies showed good quality. The characteristics of all studies are shown in Table 1.

\section{Diagnostic accuracy of a-defensin for PJ}

For the laboratory-based immunoassay, the pooled diagnostic sensitivity and specificity for PJI were 0.96 (95\% confidence interval [CI] $0.90-0.98)$ and 0.97 (95\% CI 0.95-0.99), respectively. The pooled DOR and AUC were 811 (95\% CI 220-2990) and 0.99 (95\% CI $0.98-$ 1.00), respectively (Fig. 2). For the lateral flow test, the pooled sensitivity and specificity were $0.86(95 \%$ CI
$0.81-0.91$ ) and 0.96 (95\% CI $0.93-0.98)$, respectively. The pooled DOR and AUC were 148 (95\% CI 64-343) and 0.95 (95\% CI 0.93-0.97), respectively (Fig. 2). The $I^{2}$ values for the laboratory-based immunoassay and lateral flow test were both $0 \%$, indicating no potential heterogeneity.

\section{Clinical utility of a-defensin for PJI}

For the laboratory-based immunoassay, the pooled PLR and NLR were 35 (95\% CI 18.5-66.2) and 0.04 (95\% CI $0.02-0.11)$, respectively. Based on the assumption that the pre-test probability was $20 \%$, the post-test probability of PJI was $90 \%$ and $1 \%$ for the laboratory-based immunoassay, indicating positive and negative test results, respectively (Fig. 3). For the lateral flow test, the pooled PLR and NLR were 21.2 (95\% CI 11.7-38.5) and 0.14 (95\% CI 0.10-0.21), respectively. When the lateral flow test showed positive and negative test results, the posttest probability of PJI was $84 \%$ and $3 \%$, respectively (Fig. 3).

\section{Subgroup analysis}

All results from the subgroup analysis are shown in Table 2. For laboratory-based immunoassay, the diagnostic accuracy 
Table 1 Characteristics of the 19 studies in meta-analysis for the diagnosis of PJI using a-defensin

\begin{tabular}{|c|c|c|c|c|c|c|c|c|}
\hline Study & Country & $\begin{array}{l}\text { Patients } \\
\text { number }\end{array}$ & $\begin{array}{l}\text { Mean age } \\
\text { (years) }\end{array}$ & Study design & $\begin{array}{l}\text { Excluded antibiotic } \\
\text { therapy }\end{array}$ & $\begin{array}{l}\text { Site of } \\
\text { arthroplasty }\end{array}$ & $\begin{array}{l}\text { Reference } \\
\text { standard }\end{array}$ & QUADAS \\
\hline \multicolumn{9}{|c|}{ Laboratory-based immunoassay } \\
\hline $\begin{array}{l}\text { Deirmengian et al., } \\
2014 \text { [10] }\end{array}$ & USA & 95 & 67 & Prospective & N & Hip, knee & MSIS (2011) & 14 \\
\hline $\begin{array}{l}\text { Bingham et al., } 2014 \\
\text { [9] }\end{array}$ & USA & 57 & 64.2 & Retrospective & NA & Hip, knee & MSIS (2011) & 13 \\
\hline $\begin{array}{l}\text { Deirmengian et al., } \\
2014 \text { [10] }\end{array}$ & USA & 149 & 65 & Prospective & $\mathrm{N}$ & Hip, knee & MSIS (2011) & 13 \\
\hline $\begin{array}{l}\text { Deirmengian et al., } \\
2014 \text { [10] }\end{array}$ & USA & 46 & 65 & Prospective & N & Hip, knee & MSIS (2011) & 13 \\
\hline $\begin{array}{l}\text { Frangiamore et al., } \\
2016 \text { [15] }\end{array}$ & USA & 78 & 63.3 & Prospective & NA & Hip, knee & MSIS (2011) & 14 \\
\hline $\begin{array}{l}\text { Bonanzinga et al., } \\
2017 \text { [19] }\end{array}$ & Germany & 156 & NA & Prospective & $\mathrm{N}$ & Hip, knee & MSIS (2013) & 14 \\
\hline $\begin{array}{l}\text { Gehrke et al., } \\
2018 \text { [23] }\end{array}$ & Germany & 173 & NA & Prospective & Y & Hip, knee & MSIS (2013) & 14 \\
\hline $\begin{array}{l}\text { Kanwar et al., } \\
2018 \text { [24] }\end{array}$ & USA & 70 & 66 & Retrospective & NA & Hip, knee & MSIS (2013) & 14 \\
\hline $\begin{array}{l}\text { Sigmund et al., } \\
2018 \text { [42] }\end{array}$ & Germany & 71 & 70 & Retrospective & Y & Hip, knee & MSIS (2013) & 13 \\
\hline $\begin{array}{l}\text { Stone et al., } \\
2018 \text { [43] }\end{array}$ & USA & 183 & 65.7 & Retrospective & Y & Hip, knee & MSIS (2011) & 14 \\
\hline $\begin{array}{l}\text { Kelly et al., } \\
2018 \text { [39] }\end{array}$ & USA & 32 & 64 & Retrospective & $N$ & Hip, knee & MSIS (2013) & 13 \\
\hline \multicolumn{9}{|l|}{ Lateral flow test } \\
\hline $\begin{array}{l}\text { Kasparek et al., } \\
2016 \text { [16] }\end{array}$ & Austria & 40 & NA & Retrospective & Y & Hip, knee & MSIS (2013) & 13 \\
\hline $\begin{array}{l}\text { Suda et al., } \\
2017 \text { [21] }\end{array}$ & Germany & 28 & 67.7 & Prospective & $\mathrm{N}$ & Hip, knee & MSIS (2013) & 13 \\
\hline $\begin{array}{l}\text { Balato et } \\
\text { al., } 2018 \text { [17] }\end{array}$ & Italy & 51 & 63 & Prospective & Y & Knee & MSIS (2013) & 12 \\
\hline $\begin{array}{l}\text { Berger et al., } \\
2017 \text { [18] }\end{array}$ & Belgium & 121 & 63.5 & Prospective & $\mathrm{N}$ & Hip, knee & MSIS (2011) & 14 \\
\hline $\begin{array}{l}\text { Gehrke et al., } \\
2018 \text { [23] }\end{array}$ & Germany & 191 & NA & Prospective & Y & Hip, knee & MSIS (2013) & 14 \\
\hline $\begin{array}{l}\text { Plate et al., } \\
2018 \text { [26] }\end{array}$ & Switzerland & 109 & 65 & Prospective & Y & Hip, knee & MSIS (2013) & 13 \\
\hline $\begin{array}{l}\text { de Saint Vincent } \\
\text { et al., } 2018 \text { [22] }\end{array}$ & French & 39 & 62 & Prospective & $N$ & Hip, knee & MSIS (2013) & 12 \\
\hline $\begin{array}{l}\text { Riccio et al., } \\
2018 \text { [41] }\end{array}$ & Italy & 71 & 69 & Retrospective & $\mathrm{N}$ & Hip, knee & MSIS (2013) & 13 \\
\hline $\begin{array}{l}\text { Sigmund et } \\
\text { al., } 2018\end{array}$ & Germany & 71 & 70 & Retrospective & Y & Hip, knee & MSIS (2013) & 13 \\
\hline $\begin{array}{l}\text { Renz et al., } \\
2018 \text { [40] }\end{array}$ & Germany & 221 & 70 & Prospective & $\mathrm{N}$ & Hip, knee & MSIS (2013) & 14 \\
\hline
\end{tabular}

PJI periprosthetic joint infection, NA not available, MSIS Musculoskeletal Infection Society, QUADAS Quality Assessment of Diagnostic Accuracy Studies

of $\alpha$-defensin for PJI in the studies that excluded metallosis was higher than that in the studies that included patients with metallosis. The sensitivity and specificity of the former group were 0.97 (95\% CI $0.88-0.99$ ) and 0.99 (95\% CI $0.96-1.00)$, respectively. The sensitivity and specificity of the latter group were 0.94 (95\% CI $0.84-0.98)$ and 0.96 (95\% CI 0.94-0.97), respectively. In addition, the diagnostic accuracy of immunoassay for the diagnosis of PJI was higher in prospective studies compared to retrospective studies. The pooled sensitivity and specificity of the prospective studies were 0.97 (95\% CI $0.92-0.99)$ and 0.98 (95\% CI 0.96-0.99), respectively. The pooled sensitivity and specificity of the retrospective studies were 0.91 (95\% CI $0.79-0.96$ ) and 0.95 (95\% CI 0.90-0.98), respectively. 


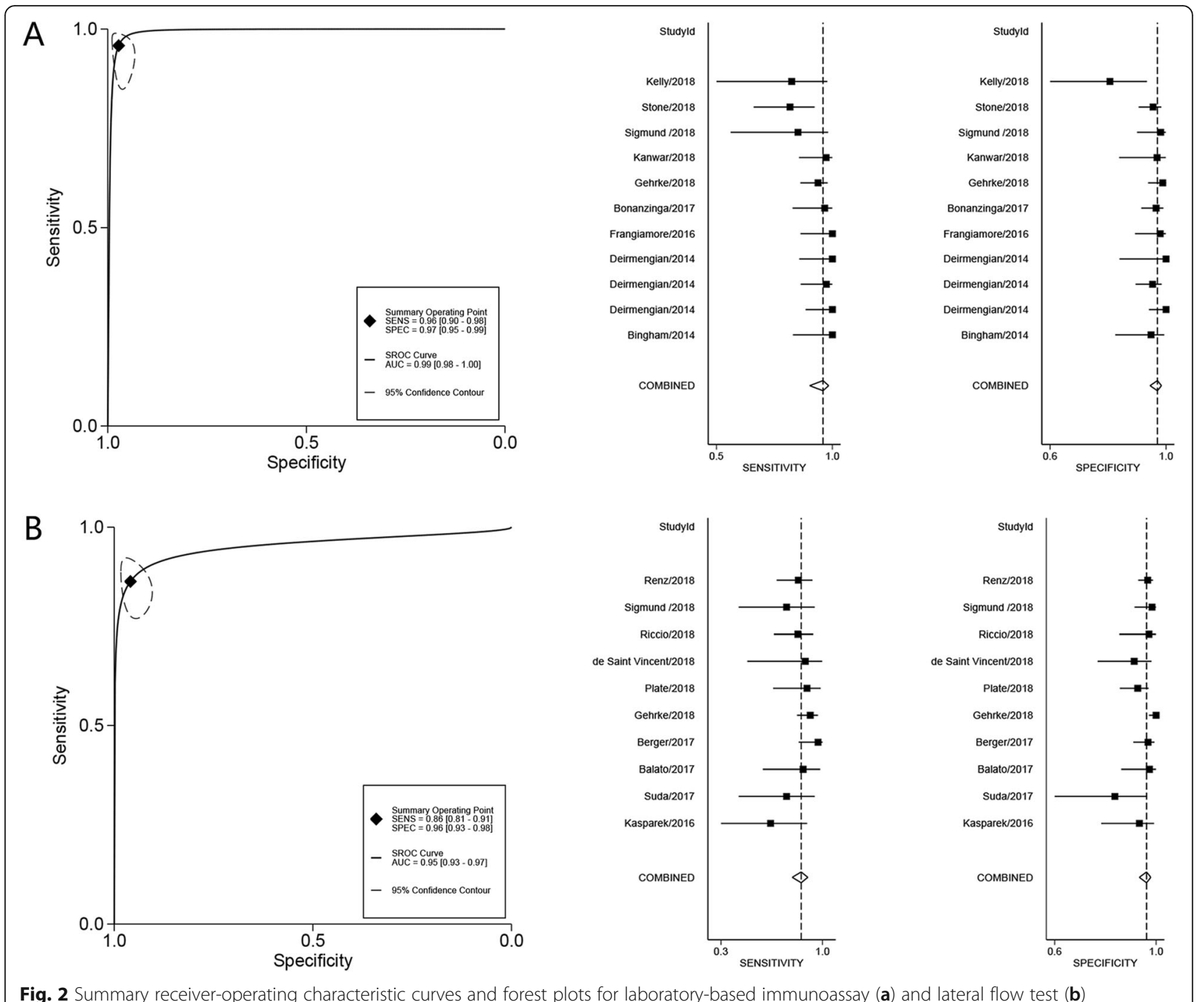

For the lateral flow test, the diagnostic accuracy of $\alpha$ defensin for PJI was similar in studies that excluded patients receiving antibiotic therapy and studies that included patients treated with antibiotics. The sensitivity and specificity of the former group were 0.86 (95\% CI 0.77-0.92) and 0.97 (95\% CI 0.91-0.99), respectively. The sensitivity and specificity of the latter group were 0.87 (95\% CI $0.78-0.92)$ and 0.95 (95\% CI 0.91-0.97), respectively.

\section{Publication bias}

There were potential publication biases in the studies of lateral flow test $(p=0.01)$ and no laboratory-based immunoassay ( $p=0.55)$ (Fig. 4).

\section{Discussion}

The current meta-analysis showed that synovial fluid $\alpha$ defensin is a valuable indicator for hip and knee PJI. Laboratory-based immunoassay can provide a reliable preoperative diagnostic basis for the presence or absence of PJI due to its extremely high sensitivity (0.96) and specificity (0.97). Despite the low sensitivity (0.86) of the lateral flow test, it is still a good intraoperative confirmation tool for PJI based on its excellent specificity (0.96).

Accurate and timely diagnosis of PJI can avoid delays in PJI treatment on the one hand, and unnecessary surgical trauma and economic losses on the other. Unfortunately, traditional methods are often difficult to distinguish PJI from aseptic loosening. The current meta-analysis showed that laboratory-based immunoassay for the detection of $\alpha$-defensin has very high diagnostic accuracy for PJI, with a sensitivity and specificity of 0.96 and 0.97 , respectively. To the best of our knowledge, no method has been reported to have such a high diagnostic accuracy for PJI (Table 3). In addition, a previous study demonstrated that the gene expression of $\alpha$ defensin in neutrophils is a specific immune response to 
A
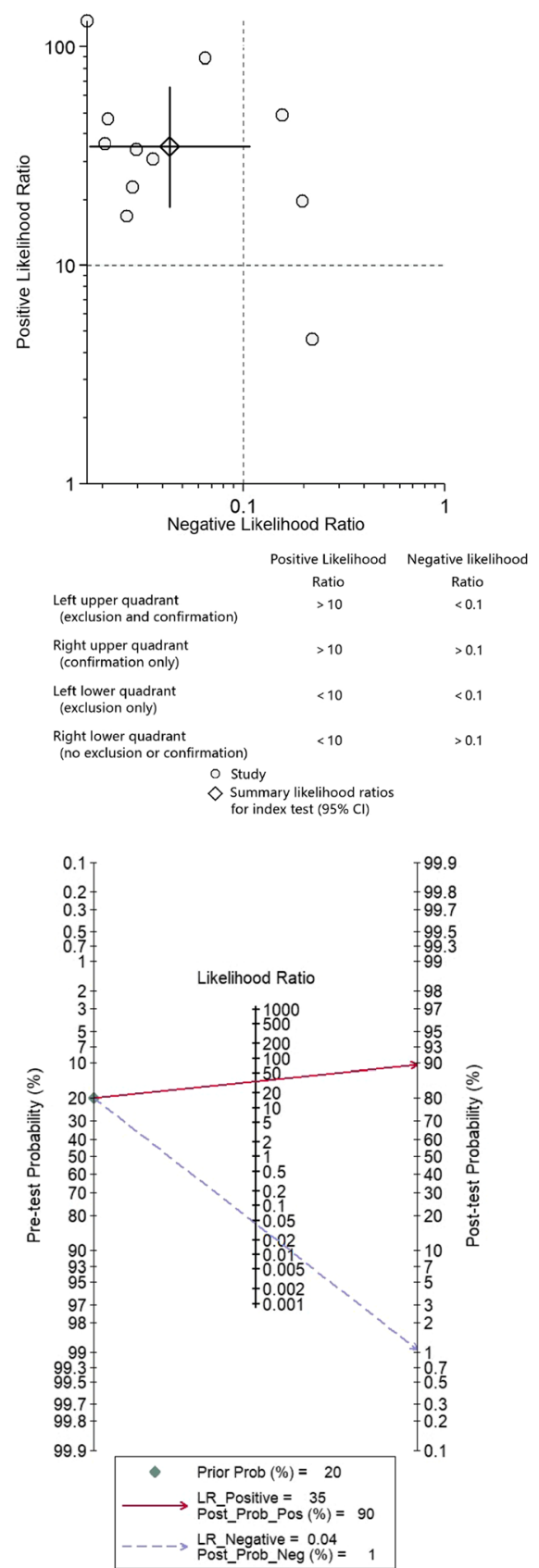

B
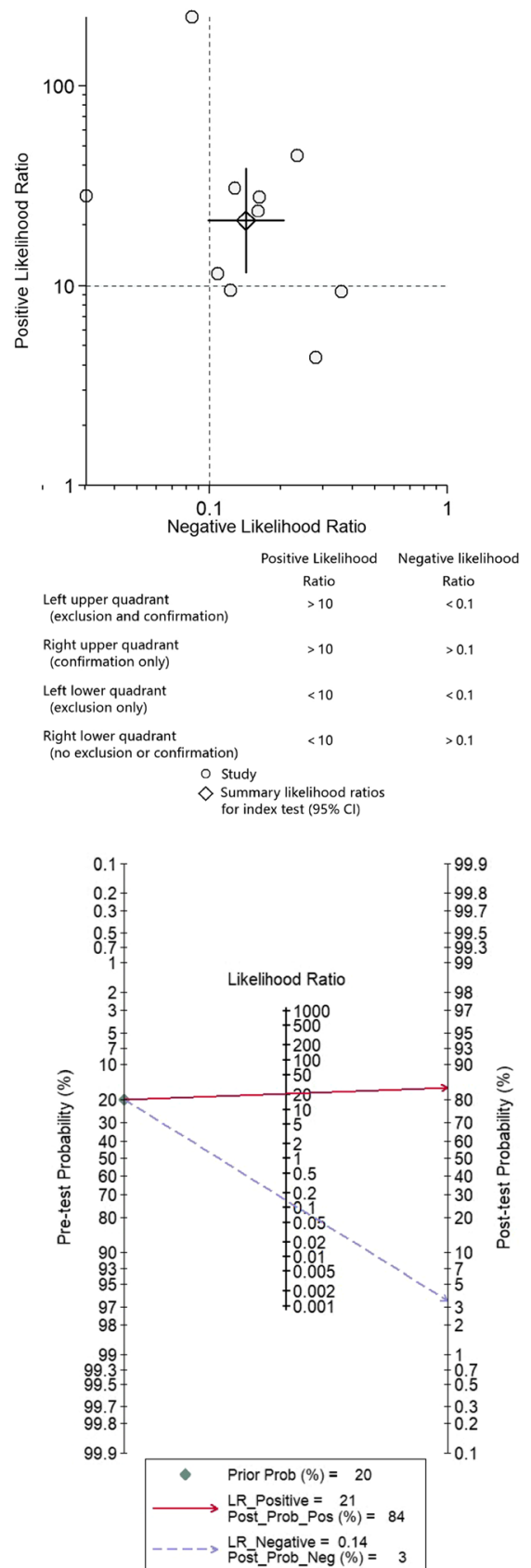

Fig. 3 Likelihood ratio scatter diagrams and post-test probabilities for laboratory-based immunoassay (a) and lateral flow test (b)

infectious inflammation, which is not affected by non-infectious inflammation and the use of antibiotics [32]. Subsequent diagnostic studies have confirmed this observation [10-12, 19, 51]. Furthermore, a large-sample (1937 samples) study conducted by Deirmengian et al. [13] showed that the test has consistent diagnostic accuracy for PJI regardless of the organism type, gram type, species, or virulence of the organism. However, the only study for shoulder PII showed that the laboratory- based immunoassay has low sensitivity (0.63) [14]. The authors of that study believed that the more commonly indolent organisms in shoulder PJI were responsible for its low sensitivity, but this conjecture was inconsistent with previous studies. The diagnostic accuracy of laboratory-based immunoassay for shoulder PJI requires additional studies. In addition, this test requires the delivery of a synovial fluid sample to an advanced laboratory for standard ELISA within $24 \mathrm{~h}$. Therefore, the time delay 
Table 2 Subgroup analysis of laboratory-based immunoassay and lateral flow test for PJ diagnosis

\begin{tabular}{|c|c|c|c|c|c|c|c|c|}
\hline $\begin{array}{l}\text { Subgroup } \\
\text { analyses }\end{array}$ & $\begin{array}{l}\text { No. of } \\
\text { studies }\end{array}$ & $\begin{array}{l}\text { No. of } \\
\text { patients }\end{array}$ & $\begin{array}{l}\text { Sensitivity } \\
(95 \% \mathrm{Cl})\end{array}$ & $\begin{array}{l}\text { Specificity } \\
(95 \% \mathrm{Cl})\end{array}$ & AUC $(95 \% \mathrm{Cl})$ & PLR $(95 \% C l)$ & NLR $(95 \% \mathrm{Cl})$ & DOR (95\%Cl) \\
\hline \multicolumn{9}{|c|}{ Laboratory-based immunoassay } \\
\hline Overall studies & 11 & 1110 & $0.96(0.90-0.98)$ & $0.97(0.95-0.99)$ & $\begin{array}{l}0.99(0.98- \\
1.00)\end{array}$ & $\begin{array}{l}35.0(18.5- \\
66.2)\end{array}$ & $\begin{array}{l}0.04(0.02- \\
0.11)\end{array}$ & $811(220-2990)$ \\
\hline \multicolumn{9}{|c|}{ Excluded metallosis } \\
\hline Yes & 4 & 416 & $0.97(0.88-0.99)$ & $0.99(0.96-1.00)$ & $\begin{array}{l}0.99(0.98- \\
1.00)\end{array}$ & $\begin{array}{l}80.7(26.0- \\
251.1)\end{array}$ & $\begin{array}{l}0.03(0.01- \\
0.13)\end{array}$ & $\begin{array}{l}2447(383-15 \\
647)\end{array}$ \\
\hline No and NA & 7 & 694 & $0.94(0.84-0.98)$ & $0.96(0.94-0.97)$ & $\begin{array}{l}0.98(0.96- \\
0.99)\end{array}$ & $\begin{array}{l}23.1(14.2- \\
37.6)\end{array}$ & $\begin{array}{l}0.06(0.02- \\
0.17)\end{array}$ & $382(103-1414)$ \\
\hline \multicolumn{9}{|l|}{ Study design } \\
\hline Prospective & 6 & 697 & $0.97(0.92-0.99)$ & $0.98(0.96-0.99)$ & $\begin{array}{l}0.99(0.98- \\
1.00)\end{array}$ & $\begin{array}{l}42.9(22.9- \\
80.4)\end{array}$ & $\begin{array}{l}0.03(0.01- \\
0.09)\end{array}$ & $\begin{array}{l}1480(423- \\
5172)\end{array}$ \\
\hline Retrospective & 5 & 413 & $0.91(0.79-0.96)$ & $0.95(0.90-0.98)$ & $\begin{array}{l}0.98(0.96- \\
0.99)\end{array}$ & $19.9(8.9-44.5)$ & $\begin{array}{l}0.10(0.04- \\
0.24)\end{array}$ & $207(52-830)$ \\
\hline \multicolumn{9}{|l|}{ Lateral flow test } \\
\hline Overall studies & 10 & 933 & $0.86(0.81-0.91)$ & $0.96(0.93-0.98)$ & $\begin{array}{l}0.95(0.93- \\
0.97)\end{array}$ & $\begin{array}{l}21.2(11.7- \\
38.5)\end{array}$ & $\begin{array}{l}0.14(0.10- \\
0.21)\end{array}$ & $148(64-343)$ \\
\hline \multicolumn{9}{|c|}{ Excluded antibiotic therapy } \\
\hline Yes & 5 & 462 & $0.86(0.77-0.92)$ & $0.97(0.91-0.99)$ & $\begin{array}{l}0.94(0.92- \\
0.96)\end{array}$ & $\begin{array}{l}32.7(9.3- \\
114.6)\end{array}$ & $\begin{array}{l}0.15(0.08- \\
0.25)\end{array}$ & $225(46-1099)$ \\
\hline No and NA & 5 & 471 & $0.87(0.78-0.92)$ & $0.95(0.91-0.97)$ & $\begin{array}{l}0.97(0.95- \\
0.98)\end{array}$ & $17.3(9.1-33.1)$ & $\begin{array}{l}0.14(0.08- \\
0.23)\end{array}$ & $124(46-336)$ \\
\hline \multicolumn{9}{|c|}{ Number of patients } \\
\hline$\geq 50$ & 7 & 826 & $0.89(0.84-0.92)$ & $0.97(0.94-0.99)$ & $\begin{array}{l}0.95(0.92- \\
0.96)\end{array}$ & $\begin{array}{l}30.9(15.4- \\
61.9)\end{array}$ & $\begin{array}{l}0.12(0.08- \\
0.17)\end{array}$ & $263(109-631)$ \\
\hline
\end{tabular}

PLR positive likelihood ratio, NLR negative likelihood ratio, DOR diagnostic odds ratio, AUC area under the curve

and economic costs need to be considered before performing this test.

Recently, a new method of lateral flow testing for the detection of synovial fluid $\alpha$-defensin has become available. This test is easy to use and provides results after just $10 \mathrm{~min}$ [23]. Therefore, this test could compensate for the shortcomings of laboratory-based immunoassay (time delay) and could therefore be used for the intraoperative diagnosis of PJI. One previous meta-analysis (three studies included) showed low diagnostic efficiency, with the sensitivity and specificity of this test being $77 \%$ and $91 \%$ [36]. The current study (nine studies included) showed a more promising result with the sensitivity and specificity of $86 \%$ and $96 \%$, respectively. Notably, the earliest three studies
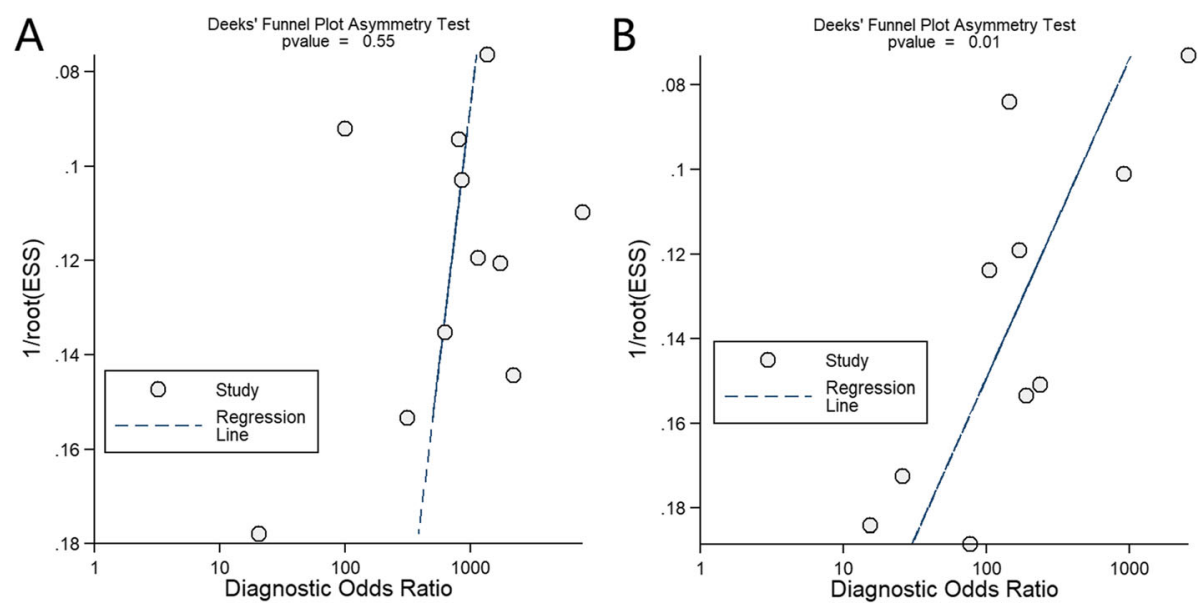

Fig. 4 Funnel plots for the included studies: laboratory-based immunoassay (a) and lateral flow test (b) 


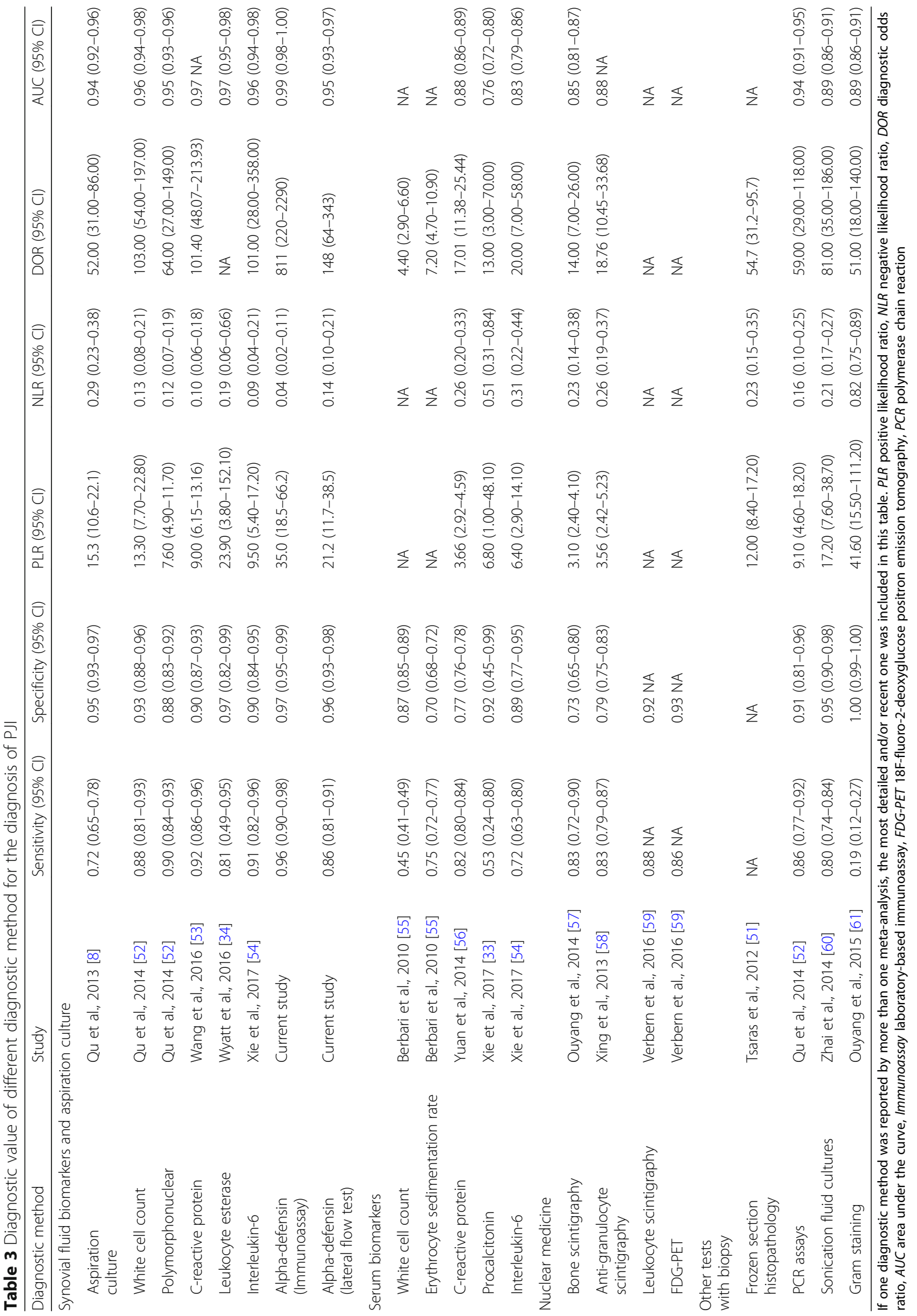


reported low sensitivity $(67-77 \%)$ for the lateral flow test to detect PJI [16, 20,21]. One of the studies [20] involved 15 patients (a total of 49 patients in the entire study) with a spacer in the studied joint, which may be a possible reason for the low sensitivity of the test. Based on the specificity of 0.96 , the lateral flow test is a valuable intraoperative confirmation tool for PJI. However, the cost-effectiveness of this test must be considered because of its high price [34, 36, 62].

It is worth noting that several studies included in the current meta-analysis showed that the presence of a communicating sinus tract increases the false-negative rate of the $\alpha$-defensin test for PJI [19, 23, 40, 42, 43]. The reason for this may be that continuous drainage reduces the concentration of $\alpha$-defensin in the synovial fluid. However, a communicating sinus is one of the major MSIS criteria and results in the diagnosis of PJI. Thus, the appearance of a communicating sinus will not have a negative impact on the application of $\alpha$-defensin testing in clinical practice. In contrast, this phenomenon indicates that $\alpha$-defensin testing has potentially higher diagnostic efficacy in clinical practice than the summary results of the current study.

In addition, regardless of which method of $\alpha$-defensin testing is used, it is necessary to guard against the presence of metallosis (adverse local tissue reaction) and crystal deposition diseases. Several studies have demonstrated that the presence of metallosis can greatly increase the likelihood of a false-positive $\alpha$-defensin result $[11,16,19,25,43]$. Deirmengian et al. [11] proposed the simultaneous detection of synovial fluid CRP levels to correct false-positive $\alpha$-defensin results. In addition, there have been reports of a tendency for false-positive $\alpha$-defensin detection in cases involving crystal deposition joint diseases, such as calcium pyrophosphate dihydrate crystal deposition disease [26]. Therefore, the accurate diagnosis of periprosthetic infections still depends on thorough examination and evaluation by orthopedists.

The current study had some limitations. First, most studies do not have long-term follow-ups for potential infection cases, which possibly increased the rate of false-negatives. Second, the included studies contained patients with acute and/or chronic PJI, whose joint fluid defensin levels may differ. The diagnostic value of these two test methods for acute and chronic PJI needs to be evaluated by specially designed studies in the future. Finally, there was potential publication bias in studies on both test methods, and this may have reduced the credibility of the findings of this study.

\section{Conclusions}

The current meta-analysis indicated that the laboratorybased immunoassay of synovial fluid $\alpha$-defensin has extremely high diagnostic accuracy for hip and knee PJI.
This method can improve the diagnostic ability of orthopedists when attempting to distinguish between PJI and aseptic loosening before revision surgery. The lateral flow test can be used as a confirmatory test for the intraoperative detection of PJI due to its excellent specificity. However, the cost-effectiveness of these two tests needs to be considered before use.

\begin{abstract}
Abbreviations
AUC: Area under the curve; CRP: C-reactive protein; DOR: Diagnostic odds ratio; ELISA: Enzyme-linked immunosorbent assay; FDG-PET: 18F-Fluoro-2deoxyglucose positron emission tomography; MSIS: Musculoskeletal Infection Society; NA: Not available; NLR: Negative likelihood ratio; PCR: Polymerase chain reaction; PJl: Periprosthetic joint infections; PLR: Positive likelihood ratio; PRISMA: Preferred Reporting Items for Systematic Reviews and MetaAnalyses; QUADAS: Quality Assessment of Diagnostic Accuracy Studies
\end{abstract}

\section{Acknowledgements}

Not applicable.

\section{Authors' contributions \\ $\mathrm{XH}$ and $\mathrm{KX}$ developed the retrieve strategy. $\mathrm{XH}, \mathrm{KX}$, and $\mathrm{XJ}$ collected the data. XH and LW participated in the data analysis. HW, XQ, and MY conceived the study design. All authors participated in manuscript preparation and approved the final manuscripts.}

\section{Funding}

This study was supported by the Project of the Shanghai Collaborative Innovation Center for Translational Medicine (Grant No. TM201814), Clinical Research Program of 9th People's Hospital affiliated to Shanghai Jiao Tong University School of Medicine (Grant No. JYL201821), Technology and Innovation Fund (Chuang Ke, Grant No. CK2018011) and the 3D Snowball Project (NO. GXQ201804) of Shanghai Jiao Tong University School of Medicine.

\section{Availability of data and materials}

The data in this study can be obtained free of charge using the search strategy in the "Methods" section.

\section{Ethics approval and consent to participate \\ Not applicable.}

\section{Consent for publication}

Not applicable.

\section{Competing interests}

The authors declare that they have no competing interests.

\section{Author details}

${ }^{1}$ Shanghai Key Laboratory of Orthopaedic Implants, Department of Orthopaedic Surgery, Shanghai Ninth People's Hospital, Shanghai Jiao Tong University School of Medicine, 639 Zhizaoju Road, Shanghai, China. ${ }^{2}$ Department of Bone and Joint Surgery, Renji Hospital, School of Medicine, Shanghai Jiao Tong University School of Medicine, 145 Middle Shandong Road, Shanghai, China.

Received: 22 October 2018 Accepted: 16 August 2019

Published online: 28 August 2019

\section{References}

1. Osmon DR, Berbari EF, Berendt AR, Lew D, Zimmerli W, Steckelberg JM, et al. Diagnosis and management of prosthetic joint infection: clinical practice guidelines by the Infectious Diseases Society of America. Clin Infect Dis. 2013;56(1):e1-e25.

2. Kurtz SM, Lau E, Schmier J, Ong KL, Zhao K, Parvizi J. Infection burden for hip and knee arthroplasty in the United States. J Arthroplast. 2008;23(7):984-91.

3. Zimmerli W, Trampuz A, Ochsner PE. Prosthetic-joint infections. N Engl J Med. 2004;351(16):1645-54.

4. Charnley J. A clean-air operating enclosure. Br J Surg. 1964;51:202-5. 
5. Bozic K, Kurtz SM, Lau E, Ong K, Chiu V, Vail TP, et al. The epidemiology of revision total knee arthroplasty in the United States. Clin Orthop Relat Res. 2010;468(1):45-51.

6. Bozic K, Kurtz SM, Lau E, Ong K, Vail TP, Berry DJ. The epidemiology of revision total hip arthroplasty in the United States. J Bone Joint Surg Am. 2009:91(1):128-33.

7. Yuan K, Li WD, Qiang Y, Cui ZM. Comparison of procalcitonin and C-reactive protein for the diagnosis of periprosthetic joint infection before revision total hip arthroplasty. Surg Infect. 2015;16(2):146-50.

8. Qu X, Zhai Z, Wu C, Jin F, Li H, Wang L, et al. Preoperative aspiration culture for preoperative diagnosis of infection in total hip or knee arthroplasty. J Clin Microbiol. 2013;51(11):3830-4.

9. Bingham J, Clarke H, Spangehl M, Schwartz A, Beauchamp C, Goldberg B. The alpha defensin-1 biomarker assay can be used to evaluate the potentially infected total joint arthroplasty. Clin Orthop Relat Res. 2014; 472(12):4006-9.

10. Deirmengian C, Kardos K, Kilmartin P, Cameron A, Schiller K, Parvizi J. Diagnosing periprosthetic joint infection: has the era of the biomarker arrived? Clin Orthop Relat Res. 2014;472(11):3254-62.

11. Deirmengian C, Kardos K, Kilmartin P, Cameron A, Schiller K, Parvizi J. Combined measurement of synovial fluid alpha-defensin and C-reactive protein levels: highly accurate for diagnosing periprosthetic joint infection. J Bone Joint Surg Am. 2014;96(17):1439-45.

12. Deirmengian C, Kardos K, Kilmartin P, Cameron A, Schiller K, Booth RE Jr, et al. The alpha-defensin test for periprosthetic joint infection outperforms the leukocyte esterase test strip. Clin Orthop Relat Res. 2015;473(1):198-203.

13. Deirmengian C, Kardos K, Kilmartin P, Gulati S, Citrano P, Booth RE Jr. The alpha-defensin test for periprosthetic joint infection responds to a wide spectrum of organisms. Clin Orthop Relat Res. 2015;473(7):2229-35.

14. Frangiamore SJ, Saleh A, Grosso MJ, Kovac MF, Higuera CA, lannotti JP, et al. Alpha-defensin as a predictor of periprosthetic shoulder infection. J Shoulder Elb Surg. 2015;24(7):1021-7.

15. Frangiamore SJ, Gajewski ND, Saleh A, Farias-Kovac M, Barsoum WK, Higuera CA. Alpha-defensin accuracy to diagnose periprosthetic joint infection-best available test? J Arthroplast. 2016;31 (2):456-60

16. Kasparek MF, Kasparek M, Boettner F, Faschingbauer M, Hahne J, Dominkus M. Intraoperative diagnosis of periprosthetic joint infection using a novel alpha-defensin lateral flow assay. J Arthroplast. 2016;31(12):2871-4.

17. Balato G, Franceschini V, Ascione T, Lamberti A, D'Amato M, Ensini A, et al. High performance of alpha-defensin lateral flow assay (Synovasure) in the diagnosis of chronic knee prosthetic infections. Knee Surg Sports Traumatol Arthrosc. 2018;26(6):1717-22.

18. Berger P, Van Cauter M, Driesen R, Neyt J, Cornu O, Bellemans J. Diagnosis of prosthetic joint infection with alpha-defensin using a lateral flow device: a multicentre study. Bone Joint J. 2017;99-b(9):1176-82.

19. Bonanzinga T, Zahar A, Dutsch M, Lausmann C, Kendoff D, Gehrke T. How reliable is the alpha-defensin immunoassay test for diagnosing periprosthetic joint infection? A prospective study. Clin Orthop Relat Res. 2017:475(2):408-15.

20. Sigmund IK, Holinka J, Gamper J, Staats K, Bohler C, Kubista B, et al. Qualitative alpha-defensin test (Synovasure) for the diagnosis of periprosthetic infection in revision total joint arthroplasty. Bone Joint J. 2017;99-b(1):66-72.

21. Suda AJ, Tinelli M, Beisemann ND, Weil Y, Khoury A, Bischel OE. Diagnosis of periprosthetic joint infection using alpha-defensin test or multiplex-PCR: ideal diagnostic test still not found. Int Orthop. 2017;41(7):1307-13.

22. de Saint VB, Migaud H, Senneville E, Loiez C, Pasquier G, Girard J, et al. Diagnostic accuracy of the alpha defensin lateral flow device (Synovasure) for periprosthetic infections in microbiologically complex situations: a study of 42 cases in a French referral centre. Orthop Traumatol Surg Res. 2018; 104(4):427-31.

23. Gehrke T, Lausmann C, Citak M, Bonanzinga T, Frommelt L, Zahar A. The accuracy of the alpha defensin lateral flow device for diagnosis of periprosthetic joint infection: comparison with a gold standard. J Bone Joint Surg Am. 2018;100(1):42-8.

24. Kanwar S, Al-Mansoori AA, Chand MR, Villa JM, Suarez JC, Patel PD. What is the optimal criteria to use for detecting periprosthetic joint infections before total joint arthroplasty? J Arthroplast. 2018;33(7S):S201-S4

25. Okroj KT, Calkins TE, Kayupov E, Kheir MM, Bingham JS, Beauchamp CP, et al. The alpha-defensin test for diagnosing periprosthetic joint infection in the setting of an adverse local tissue reaction secondary to a failed metal- on-metal bearing or corrosion at the head-neck junction. J Arthroplast. 2018;33(6):1896-8.

26. Plate A, Stadler L, Sutter R, Anagnostopoulos A, Frustaci D, Zbinden R, et al. Inflammatory disorders mimicking periprosthetic joint infections may result in false positive alpha-defensin. Clin Microbiol Infect. 2018;24(11):1212 e1-6.

27. Scholten R, Visser J, Van Susante JLC, Van Loon CJM. Low sensitivity of adefensin (Synovasure) test for intra-operative exclusion of prosthetic joint infection. Acta Orthop. 2018;89(3):1-3.

28. Ganz T, Selsted ME, Szklarek D, Harwig SS, Daher K, Bainton DF, et al. Defensins. Natural peptide antibiotics of human neutrophils. J Clin Invest. 1985; 76(4):1427-35.

29. Lehrer Rl, Ganz T. Defensins: endogenous antibiotic peptides from human leukocytes. CIBA Found Symp. 1992;171:276-90 discussion 90-3.

30. Agerberth B, Charo J, Werr J, Olsson B, Idali F, Lindbom L, et al. The human antimicrobial and chemotactic peptides LL-37 and alpha-defensins are expressed by specific lymphocyte and monocyte populations. Blood. 2000; 96(9):3086-93.

31. Chalifour A, Jeannin P, Gauchat JF, Blaecke A, Malissard M, N'Guyen T, et al. Direct bacterial protein PAMP recognition by human NK cells involves TLRs and triggers alpha-defensin production. Blood. 2004; 104(6):1778-83.

32. Deirmengian C, Lonner JH, Booth RE. The Mark Coventry Award: white blood cell gene expression. Clin Orthop Relat Res. 2005:440(\&NA):38-44.

33. Xie K, Qu X, Yan M. Procalcitonin and alpha-defensin for diagnosis of periprosthetic joint infections. J Arthroplast. 2017;32(4):1387-94.

34. Wyatt MC, Beswick AD, Kunutsor SK, Wilson MJ, Whitehouse MR, Blom AW. The alpha-defensin immunoassay and leukocyte esterase colorimetric strip test for the diagnosis of periprosthetic infection: a systematic review and meta-analysis. J Bone Joint Surg Am. 2016;98(12):992-1000.

35. Yuan J, Yan Y, Zhang J, Wang B, Feng J. Diagnostic accuracy of alphadefensin in periprosthetic joint infection: a systematic review and metaanalysis. Int Orthop. 2017:41(12):2447-55.

36. Suen K, Keeka M, Ailabouni R, Tran P. Synovasure 'quick test' is not as accurate as the laboratory-based alpha-defensin immunoassay: a systematic review and meta-analysis. Bone Joint J. 2018;100-b(1):66-72.

37. Eriksson HK, Nordstrom J, Gabrysch K, Hailer NP, Lazarinis S. Does the alphadefensin immunoassay or the lateral flow test have better diagnostic value for periprosthetic joint infection? A systematic review. Clin Orthop Relat Res. 2018;476(5):1065-72

38. Marson BA, Deshmukh SR, Grindlay DJC, Scammell BE. Alpha-defensin and the Synovasure lateral flow device for the diagnosis of prosthetic joint infection. Bone Joint J. 2018;100-b(6):703-11.

39. Kelly MP, Darrith B, Hannon CP, Nam D, Courtney PM, Della Valle CJ. Synovial fluid alpha-defensin is an adjunctive tool in the equivocal diagnosis of periprosthetic joint infection. J Arthroplast. 2018;33(11):3537-40

40. Renz N, Yermak K, Perka C, Trampuz A. Alpha defensin lateral flow test for diagnosis of periprosthetic joint infection: not a screening but a confirmatory test. J Bone Joint Surg Am. 2018;100(9):742-50.

41. Riccio G, Cavagnaro L, Akkouche W, Carrega G, Felli L, Burastero G. Qualitative alpha-defensin versus the main available tests for the diagnosis of periprosthetic joint infection: best predictor test? J Bone Jt Infect. 2018; 3(3):156-64

42. Sigmund IK, Yermak K, Perka C, Trampuz A, Renz N. Is the enzyme-linked immunosorbent assay more accurate than the lateral flow alpha defensin test for diagnosing periprosthetic joint infection? Clin Orthop Relat Res. 2018;476(8):1645-54

43. Stone WZ, Gray CF, Parvataneni HK, Al-Rashid M, Vlasak RG, Horodyski M, et al. Clinical evaluation of synovial alpha defensin and synovial C-reactive protein in the diagnosis of periprosthetic joint infection. J Bone Joint Surg Am. 2018;100(14):1184-90

44. Liberati A, Altman DG, Tetzlaff J, Mulrow C, Gotzsche PC, loannidis JP, et al. The PRISMA statement for reporting systematic reviews and meta-analyses of studies that evaluate health care interventions: explanation and elaboration. J Clin Epidemiol. 2009;62(10):e1-34.

45. Workgroup Convened by the Musculoskeletal Infection Society. New definition for periprosthetic joint infection. J Arthroplasty. 2011;26(8):1136-8.

46. Parvizi J, Gehrke T. Definition of periprosthetic joint infection. J Arthroplast. 2014;29(7):1331

47. Whiting P, Rutjes AW, Reitsma JB, Bossuyt PM, Kleijnen J. The development of QUADAS: a tool for the quality assessment of studies of diagnostic accuracy included in systematic reviews. BMC Med Res Methodol. 2003;3:25. 
48. Higgins JP, Thompson SG, Deeks JJ, Altman DG. Measuring inconsistency in meta-analyses. BMJ. 2003;327(7414):557-60.

49. Gardiner JC, Luo Z, Roman LA. Fixed effects, random effects and GEE: what are the differences? Stat Med. 2009;28(2):221-39.

50. Deeks JJ, Macaskill P, Irwig L. The performance of tests of publication bias and other sample size effects in systematic reviews of diagnostic test accuracy was assessed. J Clin Epidemiol. 2005;58(9):882-93.

51. Shahi A, Parvizi J, Kazarian GS, Higuera C, Frangiamore S, Bingham J, et al. The alpha-defensin test for periprosthetic joint infections is not affected by prior antibiotic administration. Clin Orthop Relat Res. 2016;474(7):1610-5.

52. Qu X, Zhai Z, Liu X, Li H, Wu C, Li Y, et al. Evaluation of white cell count and differential in synovial fluid for diagnosing infections after total hip or knee arthroplasty. PLoS One. 2014;9(1):e84751.

53. Wang C, Wang Q, Li R, Duan JY, Wang CB. Synovial Fluid C-reactive Protein as a Diagnostic Marker for Periprosthetic Joint Infection: A Systematic Review and Meta-analysis. Chin Med J (Engl). 2016;129(16):1987-93.

54. Xie K, Dai K, Qu X, Yan M. Serum and Synovial Fluid Interleukin-6 for the Diagnosis of Periprosthetic Joint Infection. Sci Rep. 2017;7(1):1496.

55. Berbari E, Mabry T, Tsaras G, Spangehl M, Erwin PJ, Murad MH, et al. Inflammatory blood laboratory levels as markers of prosthetic joint infection: a systematic review and meta-analysis. J Bone Joint Surg Am. 2010;92(11): 2102-9.

56. Yuan $\mathrm{K}$, Chen HL, Cui ZM. Diagnostic Accuracy of C-Reactive Protein for Periprosthetic Joint Infection: A Meta-Analysis. Surgical Infections.2014;15(5): 548-59.

57. Ouyang Z, Li H, Liu X, Zhai Z, Li X. Prosthesis infection: diagnosis after total joint arthroplasty with three-phase bone scintigraphy. Ann Nucl Med. 2014; 28(10):994-1003.

58. Xing D, Ma X, Ma J, Wang J, Chen Y, Yang Y. Use of anti-granulocyte scintigraphy with $99 \mathrm{mTc}$-labeled monoclonal antibodies for the diagnosis of periprosthetic infection in patients after total joint arthroplasty: a diagnostic meta-analysis. PLoS One. 2013;8(7):e69857.

59. Verberne SJ, Raijmakers PG, Temmerman OP. The Accuracy of Imaging Techniques in the Assessment of Periprosthetic Hip Infection: A Systematic Review and Meta-Analysis. J Bone Joint Surg Am. 2016;98(19):1638-45.

60. Zhai Z, Li H, Qin A, Liu G, Liu X, Wu C, et al. Meta-analysis of sonication fluid samples from prosthetic components for diagnosis of infection after total joint arthroplasty. J Clin Microbiol. 2014;52(5):1730-6.

61. Ouyang Z, Zhai Z, Qin AN, Li H, Liu X, Qu X, et al. Limitations of Gram staining for the diagnosis of infections following total hip or knee arthroplasty. Exp Ther Med. 2015;9(5):1857-64.

62. Tsaras G, Maduka-Ezeh A, Inwards CY, Mabry T, Erwin PJ, Murad MH, et al. Utility of intraoperative frozen section histopathology in the diagnosis of periprosthetic joint infection: a systematic review and meta-analysis. J Bone Joint Surg Am. 2012;94(18):1700-11.

\section{Publisher's Note}

Springer Nature remains neutral with regard to jurisdictional claims in published maps and institutional affiliations.

\section{Ready to submit your research? Choose BMC and benefit from:}

- fast, convenient online submission

- thorough peer review by experienced researchers in your field

- rapid publication on acceptance

- support for research data, including large and complex data types

- gold Open Access which fosters wider collaboration and increased citations

- maximum visibility for your research: over $100 \mathrm{M}$ website views per year

At BMC, research is always in progress.

Learn more biomedcentral.com/submissions 